\title{
HIV/AIDS Related Stigma among Male Labor Migrants in Nepal
}

\author{
Sushma Dahal ${ }^{1 *}$, Paras Kumar Pokharel ${ }^{2}$, Birendra Kumar Yadav ${ }^{2}$ \\ ${ }^{1}$ Department of Public Health, Central Institute of Science and Technology Baneshwor, Kathmandu, Nepal; ${ }^{2}$ School of Public Health \\ \& Community Medicine, BP Koirala Institute of Health Sciences, Dharan, Nepal. \\ Email: *sush.dahal@gmail.com
}

Received August 22 ${ }^{\text {nd }}, 2013$; revised September 21 $1^{\text {st }}, 2013$; accepted September $26^{\text {th }}, 2013$

Copyright (C) 2013 Sushma Dahal et al. This is an open access article distributed under the Creative Commons Attribution License, which permits unrestricted use, distribution, and reproduction in any medium, provided the original work is properly cited.

\begin{abstract}
Labor migrants are those of the at-risk groups for HIV. This cross-sectional study has tried to examine HIV/AIDS-related stigma among Nepalese returnee male labor migrants. Migrant workers who have worked at least six months abroad were asked different questions related to sexual behavior, knowledge on HIV/AIDS \& condom and HIV/AIDS-related stigma. Stigma was measured on a three-point rating scale as high, average and low stigma. About $58 \%$ of migrants had the view "I would rather not know if I have HIV" followed by "I don't want to be friends with people living with HIV" (53.6\% migrants) and "people with HIV are cursed" (35.5\% migrants). High stigma was present among 15.5\% of the total respondents with high proportion among those with higher age, lower education, rural residence, and no knowledge on Voluntary Counseling and Testing (VCT) service. About a quarter of respondents were of the view that migrants infected with HIV while abroad should not be allowed to return Nepal. Some level of stigma on HIV/AIDS exists among male labor migrants in Nepal. Interventions aiming at reducing stigma should consider the factors like migrants' age, education, place of residence and knowledge on VCT services.
\end{abstract}

Keywords: HIV/AIDS; Labor Migrants; Nepal; Stigma; VCT

\section{Introduction}

Migration is as an essential and inevitable component of the economic and social life of every state [1]. Nepalese government is promoting overseas employment opportunities for its citizens because of poor absorption of growing labor force in the country [2]. Political instability, especially since the onset of armed conflict has also increased the number of labor migrants [3]. Nepal today is well recognized as the country of origin for labor migrants mainly to the Gulf Cooperation Council and Malaysia. Most popular countries of destination include Qatar, Saudi Arabia, South Korea, Lebanon, Japan, Israel, Malaysia, Kuwait and United Arab Emirate [4].

Ministry of Labor and Transport management in Nepal estimates that at current there are 3 million Nepali people under foreign employment and approximately $900 \mathrm{mi}-$ grant workers leave the country for overseas employment everyday [4]. Different factors like socio-cultural patterns of host country, economic transition of migrants,

*Corresponding author. reduced availability and accessibility of health services and difficulty of host country health care system to cope with the tradition and practices of immigrants caused migrant population at increased risk of poor health and other conditions like HIV and STIs [5]. Among different Most At Risk Population (MARP) for HIV in Nepal [6], male labor migrants and the clients of FSW are the important bridging population that transmits HIV from high risk group to the general population. According to National Centre for AIDS and STD Control [7] 2011 in Nepal, male labor migrants accounted for $27 \%$ of the total HIV infections [7]. However the data represent the migrants going to India.

In Nepal there exist strong traditional norms and beliefs related to sex and sexuality related topics [8]. These topics are rarely discussed in Nepalese families where sexual activities outside marriage are also not accepted [9]. In school curriculum though sex education has been included, adolescents in school get very little information about sex education, and the major reasons behind include teachers' lack of desire and skill to deliver the sen- 
sitive contents and poor environment for students to learn about the topics enthusiastically [10]. Similarly, for those who want to obtain relevant information and services related to sexual health, there is very inadequate provision of those services in Nepal [11]. These results in the lack of knowledge about sex, sexuality, hygienic sexual behaviors, and sexually transmitted infections like AIDS etc. In case of HIV/AIDS, HIV which is infectious and potentially terminable in nature leads to fear of contracting it, its relation to sexual activity especially promiscuity \& homosexuality and immoral or irresponsible behaviors, concern of uninfected towards their own material wellbeing, underestimation of their own risk by uninfected etc. play important roles in making it a stigmatized disease. This stigma has also been found to be used as a device to maintain social order [12]. However, these reasons are not sufficient to explain the HIV/AIDS-related stigma. So, HIV/AIDS-related stigma is considered as being multi-faceted and it is expected to differ from other forms of prejudice [13].

HIV/AIDS-related stigma creates barrier to effective HIV prevention and care programs. People fear discrimination and thus avoid the testing services. People Living with HIV/AIDS (PLHA) may receive substandard treatment, may refuse to disclose their status to partners or change their behavior to avoid negative reactions. Since they neither seek care and support nor disclose it to their partners/families and thus contribute to further transmission of the disease in future [14]. People at risk of HIV are less likely to access the quality treatment and care as a result of shame associated with HIV/AIDS. The situation is likely to be more severe when the targeted service users are migrant workers who are considered as MARP. These ultimately lead to increased transmission, morbidity and mortality [15]. Thus, as a consequence of stigma, on the one hand migrant workers are likely to discriminate PLHA and on the other hand, they themselves are less likely to utilize preventive and curative services particularly related to HIV/AIDS. Similarly, those migrant workers contracting HIV are also more likely to conceal their disease status $[16,17]$, which results in low or even no use of health services.

\section{Methods}

\subsection{Study Design, Setting and Data Collection}

A cross-sectional study was done from September 2009 to February 2010 among 110 Nepalese male labor migrants returning after at least 6 months of work experience from any of the countries or areas: Qatar, Saudi Arabia, UAE, Oman, Kuwait, Bahrain, Iraq, Israel, Maldives, Malaysia, Singapore, Hong Kong, Brunei, Macao, Saipan, South Korea, Kosovo, Latvia, the Seychelles and South Africa within 3 months to 2 years from date of interview were included. The data were collected from three different cities of three regions (Eastern, Central and Western) of Nepal. Respondents were identified and taken purposively from the recruitment agencies where migrants returned from overseas had visited either for going abroad again or for some other reasons. Besides, returnee migrants were also traced in the community to increase the sample size. Major variables included in the interviewer-administered questionnaire were socio-demographic characteristics, sexual behaviors, knowledge regarding HIV/AIDS \& condom use and HIV/AIDS related stigma.

\subsection{Data Processing and Analysis}

Fourteen statements about HIV and PLHA were designed with the help of available literatures [18-21] to measure constructs related to 1) negative attitudes and beliefs about PLHAs, 2) respondents' perception of possible discrimination faced by PLHA and 3) positive statement regarding HIV/AIDS. It included both correct statements ("yes" coded as 0 , "no" coded as 1 ) and incorrect statements (reversely coded) that were added to find out total score for each respondent. Those respondents with $(0-4)$ scores were classified as having low stigma, (5 - 9) as average stigma and (10 - 14) as high stigma.

Data was analyzed using SPSS 17 software. Descriptive statistics such as frequency, percentage, table, charts were described wherever appropriate. No any inferential statistics was applied to the data as the respondents were chosen purposively.

\section{Results}

\subsection{Level of Stigma}

Among total respondents, 66.4\% (73) had low stigma, $18.2 \%$ (20) had average stigma and $15.5 \%$ (17) had high stigma. About $58 \%$ of the respondents were of view, "I would rather not know if I have HIV", followed by about $54 \%$ with the view "I don't want to be friends with people living with HIV", 43.6\% with view "people with HIV cannot be trusted" and 35.5\% with the view "people with HIV are cursed". However, around $81 \%$ of the respondents were of view that people with HIV should not hide it (Table 1).

\subsection{Socio-Demographic Information}

Table 2 presents the cross tabulation between socio-demographic characteristics of the respondents and the level of AIDS related stigma. About 23\% of respondents aged 20 - 29 years had average or high stigma which was about $43 \%$ in 30 - 39 years and about $67 \%$ in 39 years and above. Three out of four respondents who were illiterate had high stigma. About $38 \%$ of the respondents 
Table 1. Respondents view on statements related to HIV/AIDS (to measure level of stigma).

\begin{tabular}{|c|c|c|}
\hline Statements & Agree & Disagree \\
\hline 1) AIDS attacks homosexuals or bisexuals & $19(17.3)$ & $91(82.7)$ \\
\hline 2) People around would leave if I have HIV & $32(29.1)$ & 78 (70.9) \\
\hline 3) I would rather not know if I have HIV & $64(58.2)$ & $46(41.8)$ \\
\hline 4) People who have HIV/AIDS are dirty & $28(25.5)$ & $82(74.5)$ \\
\hline 5) People with HIV/AIDS are cursed & $39(35.5)$ & $71(64.5)$ \\
\hline 6) People with HIV/AIDS cannot be trusted & $48(43.6)$ & $62(56.4)$ \\
\hline 7) People with HIV/AIDS should be ashamed & $35(31.8)$ & $75(68.2)$ \\
\hline 8) People with HIV/AIDS are punished because they have done something wrong & $38(34.5)$ & $72(65.5)$ \\
\hline 9) People with HIV should be isolated & $24(21.8)$ & $86(78.2)$ \\
\hline 10) I don't want to be friends with people living with HIV & $59(53.6)$ & $51(46.4)$ \\
\hline 11) I am afraid of people living with HIV & $25(22.7)$ & 85 (77.3) \\
\hline 12) People with HIV should not be allowed to work & $26(23.6)$ & $84(76.4)$ \\
\hline 13) People with HIV are like everybody else & $72(65.5)$ & $38(34.5)$ \\
\hline 14) People with HIV should not hide it & 89 (80.9) & $21(19.1)$ \\
\hline
\end{tabular}

Numbers in parenthesis indicate percentage of row total.

Table 2. Socio-demographic characteristics and level of stigma.

\begin{tabular}{|c|c|c|c|}
\hline \multirow{2}{*}{ Socio-demographic characteristics $(n=110)$} & \multicolumn{3}{|c|}{ Number of respondents } \\
\hline & Low stigma & Average stigma & High stigma \\
\hline \multicolumn{4}{|l|}{ Age category of the respondent } \\
\hline 20 - 29 years & $41(77.3)$ & $4(7.5)$ & $8(15.1)$ \\
\hline 30 - 39 years & $31(57.4)$ & $15(27.7)$ & $8(14.8)$ \\
\hline More than 39 years & $1(33.3)$ & $1(33.3)$ & $1(33.3)$ \\
\hline \multicolumn{4}{|l|}{ Education category of the respondent } \\
\hline Illiterate & $0(0)$ & $1(25)$ & $3(75)$ \\
\hline Primary education & $0(0)$ & $6(31.6)$ & $13(68.4)$ \\
\hline Lower secondary and secondary & $51(81.0)$ & $11(17.4)$ & $1(1.6)$ \\
\hline Higher secondary and above & $22(91.6)$ & $2(8.3)$ & $0(0)$ \\
\hline \multicolumn{4}{|l|}{ Place of origin } \\
\hline$V D C$ & $40(61.5)$ & $14(21.5)$ & $11(16.9)$ \\
\hline Municipality & $33(73.3)$ & $6(13.3)$ & $6(13.3)$ \\
\hline \multicolumn{4}{|l|}{ Years spent in overseas } \\
\hline Less than or equal to 2 years & $16(84.2)$ & $3(15.8)$ & $0(0)$ \\
\hline 2 - 4 years & $42(67.7)$ & $9(14.5)$ & $11(17.7)$ \\
\hline More than 4 years & 15 (51.7) & $8(27.6)$ & $6(20.7)$ \\
\hline
\end{tabular}

Numbers in parenthesis indicate percentage of row total.

from VDC residence had average or high stigma compared to about $27 \%$ of those from municipality. With the increase in the years of overseas employment, the level of stigma was high. About $16 \%$ of migrants who had 
worked on average up to 2 years or less abroad had high stigma compared to about $32 \%$ who worked for 2 - 4 years and about $48 \%$ of those who worked more than 4 years.

\subsection{Sexual Behavior, Risk Perception and VCT Service Use}

Table 3 presents the cross tabulation of stigma with sexual behavior, condom use, HIV test, STI diagnosis and respondents' self rated risk of contracting HIV (low risk, average risk and high risk). Respondents having and not having any sexual intercourse in the overseas did not have much difference in the level of high stigma (14.8\% vs. $16.1 \%)$. However, in relation to the type of sexual partner, high difference was present; $43.5 \%$ of those having sex with girlfriend and $26 \%$ of those having sex with FSW had average or high level of stigma. Relatively higher percent of those ever diagnosed with STI had high average or high stigma (42.9\%) than those who were never diagnosed (33\%). Respondents who perceived themselves at low risk of contracting HIV/AIDS had higher stigmatizing attitude than those who perceived

Table 3. Factors related to sexual behavior, risk perception and VCT service use.

\begin{tabular}{|c|c|c|c|}
\hline \multirow{2}{*}{ Factors related to sexual behavior, risk perception and VCT service use } & \multicolumn{3}{|c|}{ Number of respondents } \\
\hline & Low stigma & Average stigma & High stigma \\
\hline \multicolumn{4}{|l|}{ Had any sexual intercourse in the overseas $(n=110)$} \\
\hline Yes & $36(66.7)$ & $10(18.5)$ & $8(14.8)$ \\
\hline No & $37(66.1)$ & $10(17.8)$ & $9(16.1)$ \\
\hline \multicolumn{4}{|l|}{ If yes, with whom? $(n=54)$} \\
\hline Girlfriend & $13(56.5)$ & $8(34.8)$ & $2(8.7)$ \\
\hline Female Sex Worker (FSW) & $22(74.1)$ & $2(7.4)$ & $5(18.5)$ \\
\hline Both girlfriend and FSW & $3(75)$ & $0(0)$ & $1(25)$ \\
\hline \multicolumn{4}{|l|}{ Frequency of sex in a month } \\
\hline Less than or equal to 1 time & $15(75)$ & $2(10)$ & $3(15)$ \\
\hline 2 - 5 times & $15(60)$ & $6(24)$ & $4(16)$ \\
\hline 6 times and above & $6(66.7)$ & $2(22.2)$ & $1(11.1)$ \\
\hline \multicolumn{4}{|l|}{ Use of condom during sexual intercourse } \\
\hline Always & $22(66.7)$ & $5(15.1)$ & $6(18.2)$ \\
\hline Sometimes & $14(70)$ & $4(20)$ & $2(10)$ \\
\hline Never & $0(0)$ & $1(100)$ & $0(0)$ \\
\hline \multicolumn{4}{|l|}{ Diagnosed with STIs before } \\
\hline Yes & $4(57.1)$ & $2(28.6)$ & $1(14.3)$ \\
\hline No & $69(67.0)$ & $18(17.5)$ & $16(15.5)$ \\
\hline \multicolumn{4}{|l|}{ Risk perceived of contracting HIV for oneself } \\
\hline Low risk & $64(64.6)$ & $19(19.2)$ & $16(16.2)$ \\
\hline Average risk & 7 (77.8) & $1(11.1)$ & $1(11.1)$ \\
\hline High risk & $2(100)$ & $0(0)$ & $0(0)$ \\
\hline \multicolumn{4}{|l|}{ Ever test for HIV by oneself } \\
\hline Yes & $49(65.3)$ & $16(21.3)$ & $10(13.3)$ \\
\hline No & $24(68.6)$ & $4(11.4)$ & $7(20.0)$ \\
\hline \multicolumn{4}{|l|}{ Use of VCT service } \\
\hline Yes & 7 (87.5) & $1(12.5)$ & $0(0)$ \\
\hline No & $66(64.7)$ & $19(18.6)$ & $17(16.7)$ \\
\hline
\end{tabular}

Numbers in parenthesis indicate percentage of row total. 
themselves at average or high risk. Among the respondents who ever tested themselves for HIV, $13.3 \%$ had high stigma compared to $20 \%$ of those who never tested for HIV. $12.5 \%$ of respondents who ever used VCT service had low stigma compared to around 35\% who had never used the service. A total of 99 (90\%) respondents categorized themselves at low risk, $9(8.2 \%)$ at average risk and 2 (1.8\%) at high risk of contracting HIV/AIDS.

\subsection{Knowledge about HIV/AIDS and Condom Use}

As knowledge related to HIV/AIDS and condom use can also determine the level of HIV/AIDS related stigma, a cross tabulation of knowledge related factors was done with the stigma category. Table 4 shows that, out of 79 respondents who said women can give AIDS to men 8.8\% had high stigma compared to $32.2 \%$ respondents who said women can't give AIDS to men. Similarly, $66.67 \%$ respondents who agreed that condoms are not safe to use had average or high stigma compared to $28 \%$ respondents who had the view they are safe. About 20\% of those who disagreed condom should be used with FSW only had average or high stigma.

\subsection{View on Return of PLHA in Nepal}

Out of the total respondents, only $23.4 \%$ had known someone with AIDS. In response to a question "Any Nepalese who suffer from HIV/AIDS while in abroad, should they be permitted to return Nepal?” about 74\% said they should be permitted, $23.6 \%$ said they should not be permitted and $2.7 \%$ had no idea on this regard. Respondents' reasons behind the idea of permitting and not permitting the return of migrants suffering from HIV/AIDS were based on different themes which are presented here separately for clarity.

\section{Nepal is their country too}

A total of forty one respondents believed that every Nepalese has right to stay in Nepal. One of the respondents' comment reflecting this perspective, "Nepal is their (migrants suffering from AIDS) country too and they have right to live here with their family". Migrants said that disease status should not determine whether they stay in Nepal. As one of the respondent stated, "Though he has suffered from dangerous disease like AIDS, the door to his own country should not be closed". One of the respondents also stated that "They have right to die in their own country”.

They need love and care

Twelve respondents believed that migrants suffering from HIV/AIDS need love and care. "They should be institutionalized, loved and cared, if so they can live 5 10 years more" as commented by one of the respondents. Some were also aware about the need of providing mental support. As one respondent said "They should be psychologically supported so that further transmission could be controlled".

\section{There is no other ways out}

A total of 23 respondents also mentioned than there were no other ways out that permitting the return as the company's rule in overseas doesn't allow staying if one is found to have HIV. As one respondent commented on this perspective, "They can't live abroad if the company knows that they have HIV, they can't work, they suffer and so need their family and country". One of the respondent also stated that "they have no other place to go than their own country". Since all the respondents are the returnee migrants, they have awareness about the company's rule. Nine respondents had a similar reason stating, "If they suffer from HIV in abroad, they are highly likely to suffer more".

Table 4. Knowledge related factors and level of stigma.

\begin{tabular}{|c|c|c|c|}
\hline \multirow{2}{*}{ Knowledge related factors } & \multicolumn{3}{|c|}{ Number of respondents } \\
\hline & Low stigma & Average stigma & High stigma \\
\hline Women can give AIDS to men $(n=79)$ & $58(73.4)$ & $14(17.7)$ & $7(8.8)$ \\
\hline Women cannot give AIDS to men $(n=31)$ & $15(48.4)$ & $6(19.3)$ & $10(32.2)$ \\
\hline Agree that AIDS cannot be cured $(n=94)$ & $68(72.3)$ & $15(15.9)$ & $11(11.7)$ \\
\hline Disagree that AIDS cannot be cured $(n=16)$ & $5(31.2)$ & $5(31.2)$ & $6(37.5)$ \\
\hline Agree that condoms are not safe $(n=9)$ & $3(33.3)$ & $6(66.7)$ & 0 \\
\hline Disagree that condoms are not safe $(n=96)$ & 69 (71.9) & $14(14.6)$ & $13(13.5)$ \\
\hline Agree on the view that condom should be used with only FSW $(n=49)$ & $32(65.3)$ & $9(18.4)$ & $8(16.3)$ \\
\hline Disagree on the view that condom should be used with only FSW $(n=87)$ & $70(80.4)$ & $9(10.3)$ & $8(9.2)$ \\
\hline
\end{tabular}

Numbers in parenthesis indicate percentage of row total. 


\section{Practice risky behavior in abroad}

Some respondents' believed that if those who have suffered from HIV in abroad stay there, they are more likely to engage in other risk behavior. Some of the respondents stated that, "In foreign they are alone, their family is in Nepal. So they are free to do anything they like e.g. indulge with more partners for sex". Respondents were also aware that there more people should not suffer due to one person. As one of the respondents commented that, "In Nepal they transmit HIV to only their wife and children but in abroad they transmit it to many others".

\section{To use them for preventing HIV}

Some respondents came up with the useful interventions to prevent further transmission of HIV in Nepal with the use of migrants suffering from HIV themselves. As one of the respondents mentioned that, "they should be permitted to return Nepal if they agree to be active in spreading messages to community about prevention of HIV". Another respondent said, "they can inform people (especially prospective migrants) more effectively about how to prevent contracting HIV".

\section{They infect many people}

A total of 25 respondents gave reason related to chance of more HIV infection behind their view of no permission to be given to those suffering from HIV in abroad. Most of them had same reason stating, "If they return Nepal, they are likely to hide their disease and hence infect other innocent people in Nepal".

Other reasons mentioned behind no permission were highly stigmatizing reflected by some of the reasons stated. As two of the respondent commented, "They are doing sins by having HIV". Some respondents were also found to have felt insecure image of themselves because of those people who suffer from HIV in abroad. As one of the respondent stated, "These people with HIV create wrong impression of foreign employment to families, friends and other people who are staying in Nepal". One of the respondent mentioned "They have committed crime. So they should not be given permission to return Nepal".

\section{Discussion}

The study has tried to reveal the level of stigma on HIV/ AIDS among migrant workers. About $63 \%$ of the respondents had low stigma whereas $15.5 \%$ had high stigma.

In this and in a previous study by Wolfe et al. [17] one of the important stigmatizing attitudes is related to view that "I would rather not know if I have HIV". In Wolfe et al.'s study 94\% of respondents reported keeping their HIV positive status secret from the community. Forty percent of these reported that they delayed getting tested for HIV. More than half of these who delayed getting tested, more than half cited fear of a positive test result as the primary reason for delay in seeking treatment. The most typical form of stigmatization as described by Herek \& Glunt is rejection and status loss [22]. In the present study, this rejection was expressed by around $54 \%$ of respondents who agreed a statement that “I don't want to be friends with PLHA" and around 24\% who agreed that "PLHA should not be allowed to work". Study of expression of HIV related stigma among rural to urban migrants done by Hong et al. [23] also suggests Chinese rural-to-urban migrants' attitudes toward HIV infected individuals take forms of denial, indifference, labeling, separation, rejection, status loss, shame, hopelessness, and fear.

According to a study done in China among migrant women living in Shanghai; being older, having low levels of education and longer duration of stay in Shanghai were identified as important correlates for having stigmatizing attitude while having multiple sex partners was correlated with less stigma [18]. Similar findings were found in present study also; higher percent of older respondents had average or high stigma compared to those of younger age that is about $67 \%$ in 39 years and older, $43 \%$ in 30 - 39 years and $23 \%$ in 20 - 29 years age. Three out of four respondents who were illiterate had high level of stigma. Around $16 \%$ of respondents who had stayed in overseas for less than or equal to 2 years had average or high stigma compared to $32 \%$ of those who had stayed for 2 - 4 years and around $48 \%$ of those who had stayed for more than 4 years. Higher proportion of those having sex with multiple partner and those with higher frequency of sex had low level of stigma. Present study found that higher proportion of respondents from VDC residence had high stigma compared to respondents from municipality residence.

Previous studies [20,24-26] have shown that stigma is inversely related to HIV testing. Similar to this, present study has found that $20 \%$ of those who never tested for HIV and who had never heard of VCT service had high stigma compared to about $13 \%$ of those who had ever done HIV test.

Timely testing for HIV infection is essential for effective management of HIV as it makes the infected person informed about their serostatus and hence they can gain access to care and benefit from the available treatment options. HIV related stigma has impact on HIV testing and care [27]. According to findings from a study done in Southern borders in Brazil, higher stigmatizing attitudes were correlated with less HIV service utilization as well as unwillingness to tell anyone about an HIV-positive diagnosis [21].

According to a study by Barth KR et al. [28] among college students, social stigmas and negative consequences appear to represent significant barrier to HIV testing, which could increase the risk of spreading the 
infections to others.

The level of stigma on HIV/AIDS among migrants affects the effectiveness of HIV/AIDS prevention program by creating an environment that discourages individuals (both PLHA and people at risk) from disclosing themselves and seeking care on promotive, preventive and curative services on HIV. HIV/AIDS stigma directly or indirectly violates the human right element of at-risk group and PLHA making them suffer more.

\section{Conclusions}

Findings from this study have several implications for preventing the HIV epidemic in the future. Firstly it has tried to explore the level of stigmatizing attitude against HIV/AIDS among the labor migrants and secondly these respondents are themselves the population at risk for HIV infection in Nepal. On the one hand, the insulting attitude against HIV/AIDS presenting among the respondents directly affects their behavior towards PLHAs and on the other hand, this attitude can possibly affect their health service seeking behavior like going to a VCT center and Anti-Retroviral Therapy center etc.

Thus, programs that aim for HIV prevention should target both the prospective and returnee migrants in country of origin. Stigma reduction programs should be also designed on multifaceted nature of HIV-related stigma and focus should be among migrants with no or low education, rural residence and with higher duration of people stay overseas. To reduce the stigma and make future AIDS intervention programs effective, country of destination can have important roles in conducting stigma reduction programs and making VCT services accessible to them.

\section{REFERENCES}

[1] N. Saggurti, R. K. Verma, A. Jain, et al., "HIV Risk Behaviours among Contracted and Non-Contracted Male Migrant Workers in India: Potential Role of Labour Contractors and Contractual Systems in HIV Prevention," AIDS, Vol. 22, Suppl. 5, 2008, pp. 127-136. http://dx.doi.org/10.1097/01.aids.0000343771.75023.cc

[2] G. Gurung, "Patterns in Foreign Employment and Vulnerability of Migrant Workers," Nepal Institute of Development Studies, Kathmandu, 2000.

[3] P. Bhattarai, "Policing the New Nepali Economy," Nepal Monitor, 2006.

[4] IOM, “Labour Migration,” International Organization for Migration, the Migration Agency Nepal.

[5] UNESCO/UNAIDS, "Migrant Population and HIV/AIDS, the Development and Implementation of Programmes: Theory, Methodology and Practice,” 2000.

[6] DOHS, “Annual Report,” Department of Health Services, Ministry of Health and Population, Kathmandu, 2067/68, 2010/2011.
[7] NCASC, “Nepal Country Progress Report,” Government of Nepal, Ministry of Health and Population, National Centre for AIDS and STD Control, Teku, Kathmandu, 2012.

[8] P. P. Regmi, P. P. Simkhada and E. Teijlingen, "Boys Remain Prestigious, Girls Become Prostitutes: SocioCultural Context of Relationships and Sex among Young People in Nepal," Global Journal of Health Science, Vol. 2, No. 1, 2010, pp. 60-72.

[9] J. Burbank, "Culture Shock: Nepal. A Guide to Customs and Etiquette,” Kuperard Ltd., London, 1994.

[10] S. Pokharel, A. Kulczycki and S. Shakya, "School-Based Sex Education in Western Nepal: Uncomfortable for Both Teachers and Students," Reproductive Health Matters, Vol. 14, No. 28, 2006, pp. 156-161. http://dx.doi.org/10.1016/S0968-8080(06)28255-7

[11] P. P. Regmi, P. P. Simkhada and E. Teijlingen, "Review Sexual and Reproductive Health Status among Young Peoples in Nepal: Opportunities and Barriers for Sexual Health Education and Services Utilization," Kathmandu University Medical Journal, Vol. 6, No. 2, 2008, pp. 248-256.

[12] G. M. Herek, “Thinking about AIDS and Stigma: A Psychologist's Perspective,” The Journal of Law, Medicine \& Ethics, Vol. 30, No. 4, 2002, pp. 594-607. http://dx.doi.org/10.1111/j.1748-720X.2002.tb00428.x

[13] B. L. Genberg, Z. Hlavka, K. A. Konda, et al., “A Comparison of HIV/AIDS-Related Stigma in Four Countries: Negative Attitudes and Perceived Acts of Discrimination towards People Living with HIV/AIDS," Social Science \& Medicine, Vol. 68, No. 12, 2009, pp. 2279-2287. http://dx.doi.org/10.1016/j.socscimed.2009.04.005

[14] J. Busza, "Literature Review: Challenging HIV-Related Stigma and Discrimination in Southeast Asia: Past Successes and Future Priorities,” The Population Council Inc., New York, 1999.

[15] K. Morrison, "Breaking the Cycle: Stigma, Discrimination, Internal Stigma and HIV,” Futures Group, Washington DC, 2006.

[16] R. Weitz, "Living with the Stigma of AIDS," Qualitative Sociology, Vol. 13, No. 1, 1990, pp. 23-38. http://dx.doi.org/10.1007/BF00988594

[17] W. R. Wolfe, S. Weiser, D. Bangsberg, et al., "Effects of HIV-Related Stigma among an Early Sample of Patients Receiving Antiretroviral Therapy in Botswana,” AIDS Care, Vol. 18, No. 8, 2006, pp. 931-933. http://dx.doi.org/10.1080/09540120500333558

[18] H. Cao, N. He, Q. Jiang, et al., "Stigma against HIV-Infected Persons among Migrant Women Living in Shanghai, China," AIDS Education and Prevention, Vol. 22, No. 5, 2010, pp. 445-454. http://dx.doi.org/10.1521/aeap.2010.22.5.445

[19] G. M. Herek and J. P. Capitanio, “AIDS Stigma and Sexual Prejudice,” American Behavioral Scientist, Vol. 42, No. 7, 1999, pp. 1130-1147.

[20] S. C. Kalichman and L. C. Simbayi, "HIV Testing Attitudes, AIDS Stigma, and Voluntary HIV Counselling and Testing in a Black Township in Cape Town, South Af- 
rica," Sexually Transmitted Infections, Vol. 79, No. 6, 2003, pp. 442-447. http://dx.doi.org/10.1136/sti.79.6.442

[21] J. Pulerwitz, A. Michaelis, S. Lippman, et al., "HIV-Related Stigma, Service Utilization, and Status Disclosure among Truck Drivers Crossing the Southern Borders in Brazil,” AIDS Care, Vol. 20, No. 7, 2008, pp. 764-770. http://dx.doi.org/10.1080/09540120701506796

[22] G. M. Herek and E. K. Glunt, "AIDS-Related Attitudes in the United States: A Preliminary Conceptualization,” Journal of Sex Research, Vol. 28, No. 1, 1991, pp. 99-123. http://dx.doi.org/10.1080/00224499109551597

[23] Y. Hong, X. Li, B. Stanton, et al., "Expressions of HIV-Related Stigma among Rural-To-Urban Migrants in China," AIDS Patient Care and STDs, Vol. 22, No. 10, 2008, pp. 823-831. http://dx.doi.org/10.1089/apc.2008.0001

[24] G. M. Herek, J. P. Capitanio and K. F. Widaman, "HIVRelated Stigma and Knowledge in the United States: Prevalence and Trends, 1991-1999," Journal Information, Vol. 92, No. 3, 2002, pp. 371-377.

\section{List of Abbreviations}

FSW: Female Sex Worker

MARPs: Most At Risk Population

NCASC: National Centre for AIDS and STD Control

PLHA: People Living with HIV/AIDS
[25] W. Ma, R. Detels, Y. Feng, et al., “Acceptance of and Barriers to Voluntary HIV Counselling and Testing among Adults in Guizhou Province, China," AIDS, Vol. 21, Suppl. 8, 2007, pp. s129-s135. http://dx.doi.org/10.1097/01.aids.0000304708.64294.3f

[26] A. Malcolm, P. Aggleton, M. Bronfman, et al., "HIVRelated Stigmatization and Discrimination: Its Forms and Contexts," Critical Public Health, Vol. 8, No. 4, 1998, pp. 347-370. http://dx.doi.org/10.1080/09581599808402920

[27] M. A. Chesney and A. W. Smith, "Critical Delays in HIV Testing and Care the Potential Role of Stigma,” American Behavioral Scientist, Vol. 42, No. 7, 1999, pp. 11621174. http://dx.doi.org/10.1177/00027649921954822

[28] K. R. Barth, R. L. Cook, J. S. Downs, et al., "Social Stigma and Negative Consequences: Factors that Influence College Students' Decisions to Seek Testing for Sexually Transmitted Infections,” Journal of American College Health, Vol. 50, No. 4, 2002, pp. 153-159. http://dx.doi.org/10.1080/07448480209596021

UAE: United Arab Emirates

VCT: Voluntary Counseling and Testing

VDC: Village Development Committee 